\title{
Interview with Michel Waldschmidt
}

Ulf Persson (Chalmers University of Technology, Göteborg, Sweden), Editor of the EMS Newsletter

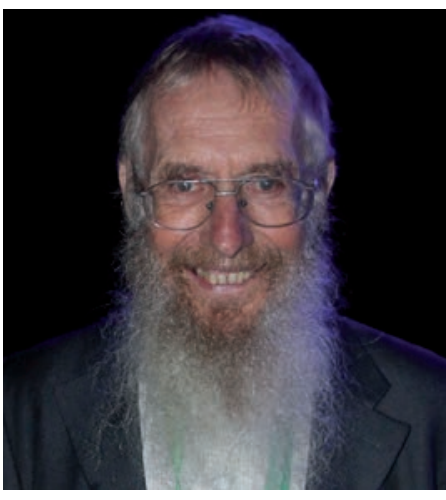

Michel Waldschmidt is a French mathematician, whose professional work has centred on number theory, especially dealing with transcendental numbers. But here he is interviewed about his passionate involvement with mathematics in the Third World, as reflected in his vice-presdency of CIMPA (Centre international de mathématiques pure et appliquées) during the years 2005-2009. He is also a member of the EMS committee CDC (Committee for Developing Countries).

\section{UP: You have travelled a lot?}

MW: One could say so: I have in fact taught in about seventy different countries.

\section{So you knew Michael Passare?}

Of course I did. So sad that it came to such a bad end in Oman. It was the heart and not a fall as we first understood.

\section{Correct.}

He was a passionate traveller: he visited 152 countries.

Yes, he was very serious about the game. Ultimately he would have wanted to visit all countries, I guess.

$\mathrm{He}$ almost achieved it. He was such a nice guy. He was also a member of the Committee for Developing Countries of the European Mathematical Society. I remember in April 2008 flying from Vienna to Venezia for a meeting of CDC EMS at ICTP thinking that it would just be a short haul to Trieste. I arrived at eight o'clock in the evening and enquired about the next train connection to Trieste and was told that there was none until the next morning! Then Michael showed up with two colleagues from Sweden and asked if I was going to the meeting in Trieste. Sure, I said. 'We have rented a car, why don't you join us,' he said. Just like that. That was very nice.

\section{You also travelled a lot in Africa.}

This is true, but Asia is my main territory. Mainly South East Asia. This year I already visited Africa three times; but I have the most experience with Asia.

What is it that you and your committee want to do? First, the CDC of the European Mathematical Society is not my committee, now I am only an associate member, but true, I have been very active in it since the turn of the millennium and I have been the chair. I am also very much involved in the activities of the CIMPA (Centre international de mathématiques pures et appliquées), of which I have been vice-president. These are two examples of institutions doing remarkably efficient work with extremely little money.

So you are the right guy to ask?

At least when it comes to South East Asia.

\section{Sorry for the interruption...}

...no problem. What we want to do is to contribute helping our colleagues from less developed countries to improve the level of mathematics there. We give lectures at the master's level, we organize workshops and research schools, we help creating networks. One of our strategies is to set up good research centres (called Emerging Research Centres of Excellence, ERCE) to which people also from neighbouring countries can travel and learn, and not have to go to the West, because this is not sustainable.

You mean just to educate a few people in the West for them to either stay in the West or to return to nothing at home is not doing anything at all?

It is better than nothing, but it is far from our goal. When we meet students who wish to get a PhD in mathematics they invariably enquire about funds for going to the West...

...this might be good for the individuals but not for the country?

It may be good for both. We tell them that it is much more efficient for them to go to an institution of international level in a neighbouring country than to go through the hassle of such a drastic relocation. And as you point out, we want to do this primarily for the country, but we mind also for the individuals. As an example, the CDC of EMS supported a young mathematician from Indonesia who went to ASSMS Lahore to pursue his studies up to his $\mathrm{PhD}$. This is a success story and we wish we had more funds to repeat it.

But individuals are concrete entities while countries are abstract ones, and I am sure that in some cases you cannot but prioritize an actual individual and his life and career.

As I see it, it is ultimately a question of justice. People like you and me had the privilege of growing up in functioning and prosperous Western democracies with good school systems and were able to follow our inclinations and become mathematicians. People all over the world should have that opportunity. We witness a fantastic 
development of higher education in all countries. Each country should have mathematicians who participate in international activities like ICM and are full members of the mathematics community, connected with mathematicians all around the world. Even in countries like Papua New Guinea or Bhutan, there are mathematicians who are eager to have international contacts. So you see ultimately it is about people as individuals. By helping the countries we help people.

And not the other way around.

Both are closely connected.

Still, you cannot just build a research institution and invite eager people like you from abroad to spend a few months lecturing. Sure it will be fun for you, as is testified by your many trips, and I would love to do it myself, but does it leave any traces? Is it not like throwing a stone into water, there is big splash, and there are some waves. But the stone sinks to the bottom and soon the water is as smooth again as it was before, and no one could suspect anything at all.

I hope it is not as bad as that. We start a program when we are asked by colleagues from the country to do so we answer their demand. I certainly believe that our efforts are not wasted but that some traces remain. In fact we have discovered some very good students in different countries and helped them, so at least on the individual level it has not been in vain.

But we are talking about sustainable changes.

You are right. In many of the developing countries, mathematics is in fact very weak. There may be universities, where mathematics is being taught, even $\mathrm{PhDs}$ given, but there is no real mathematics done, nothing new produced, and that's what research in mathematics is all about after all. Just imagine writing a $\mathrm{PhD}$ thesis which contains nothing new! The problem is that the people at the universities are isolated, often ignorant and, to be honest, for many of them, not particularly bright. Fortunately there are some remarkably motivated individuals; these are the colleagues with whom we are working. I am amazed to see how devoted they are, working in very difficult conditions. They do a tremendous job, they deserve respect, and we want to help them as much as possible. But they are not the majority. Teachers, even at universities, are badly paid and as a consequence most bright young people seek other careers. In fact some colleagues from local universities are not happy with us because we expose their shortcomings and render them superfluous, so in fact this explains that we often do not get any official support.

So that is my point: you need to develop a mathematical infrastructure and that means having a good school system at all levels, from the elementary ones up to high school.

That is very true, but it will take time, perhaps a generation or so. All that we can do is to apply a top-down approach and hope that our good influence will trickle down. By improving university teachers and hence gradu- ally also high-school teachers down to the village, we will get a positive feedback.

The educational system has two purposes. One is to look for and identify real talent in order to encourage and help; the other is to improve the general public, meaning to impart literacy and a respect for learning and culture. Those two aims are not necessarily conflicting, on the contrary; but if one has to be chosen, I would say that the first is the most important. Gauss's sadistic teacher did at least recognise Gauss's genius, and thereby doing mankind a great favor. The history of science is filled with such stories (but of course we only know about the success stories) and it is not clear that our modern Western educational system would be up to the challenge (in fact I know stories indicating the opposite).

In France we have a successful combination of the elitist system and the egalitarian one. We still maintain institutions such as École Normale Supérieure and at the same time we have the ambition that at least 90 percent of the population should get a high-school education. And I would say it works well. It shows that with mass education you can maintain the same standards as with the more elitist ones of the past.

Why should such a large percentage of the general population be subjected to a formal education they cannot profit from in an intellectual way? But this is now considered as a right on a par with clean water and medical care. The responsibility of learning no longer lies with the student but the teacher, just as it lies with the surgeon not the patient, when it comes to an operation. We are diverging a bit from the purpose of our conversation, but I agree. It is a problem of actually finding the good students. It happens that we find some promising students; before taking them to some Western institutions, we need to make sure that they have some independence of mind. In some cases it turns out that they have only learned things by heart and have no idea what it really means. Student easily memorise the axioms of topology say, but when asked questions about open sets on the real line they are stymied.

What is the point of memorizing mathematics! Whatever gave them the idea?

No point at all of course. But, I guess, in many subjects, such as history, memorization is important and inescapable.

Not even in history is it that important and there is such a thing as understanding in history as well. Things you learn that excite and stimulate you, you need not commit to memory, they become part of you automatically...

...as in mathematics.

Very true. But when it comes to languages, learning poems by heart is supposed to be very good. After all language is a kind of motor skill. But now there is so much emphasis on so-called creativity and critical thinking, 
and modern students are supposed to excel in that, while when it comes down to it, most students feel very comfortable with just memorizing, forget about creativity, as you discover whenever you give an exam with interesting problems. For many people, not the least in the Third World, education is merely a means of getting on in the world, and you do what it takes, be it to memorise meaningless facts. It is just part of a ritual.

What are you leading up to? I thought you were supposed to ask the questions and leave me to elaborate the answers.

\section{Bear with me. Be patient!}

I am trying my best, but there are limits.

My point is simply that what you need is an educational system in which the teachers have the right intellectual attitude. In particular, a math teacher would never think of memorizing mathematics but love the subject and have some talent as well. Forget about so-called teaching skills, they are just spurious, what counts is attitude and personality. In the West the traditional educational system is dismantled, the prestige of teachers has taken a nosedive, and they are now badly paid as a result. In fact until the seventies, members of the parliament in Sweden, were not supposed to be paid more than high-school teachers.

Really!

So I have been told. Ironically I think it might be easier to create a good educational system in the developing world than to reverse the trend of degeneration in the West. After all, there are a lot of poor, talented people who can be induced to take teaching as a career and earn prestige by that. Once such a system is in place, you have a foundation to build on.

You do not leave me much left to say. But I'll do my best. I agree with you, and there are countries, thought of as poor and backwards, with an excellent educational system. I would, in particular, point to Iran. And as we all know they produce excellent mathematicians without our help. Often in CIMPA research schools when some students come from Iran they are the best (and the next ones are from Vietnam). India also has excellent mathematical centers. After its independence, India decided to have the atomic bomb: a politician, Nehru, a scientist, Homi Bhabha, and an industry, Tata, created the Tata Institute of Fundamental Research in Bombay in order to acquire the necessary scientific level in physics, and this included the need to have mathematicians of the highest international level. They succeeded. I visited TIFR for the first time in 1976 and now I go to India about twice every year.

What about South Korea? In 1980 or so, only one research paper was published, and now!

I do not know much of the details about the rise of mathematics in Korea, I should as I have an in-law from Korea. It is true that the government supported strongly the development of mathematics in order to reach the highest level in technology. As a matter of fact, nowadays Korea is one of the leading countries in mathematics; the previous ICM took place in Seoul in 2014. Of course, China is a superb example of amazing increase in the mathematical level due to a very strong support by the highest authorities, who understood that a strong mathematical level is a key for technological innovation and economic development of the country.

And Japan. Japan lifted itself by the hair in connection with the Meiji restoration and entirely on its own power caught up technologically with the West, but, I guess, they had a long intellectual tradition and a solid educational system in place, which only needed some prompting.

That is true. Mathematics has a long tradition in Japan. If you ask me about South East Asia I will give you particulars.

I do.

Asia is very diverse. One real success story is Vietnam. After the wars with the French and then the Americans, French mathematicians went there. I am, in particular, thinking of Laurent Schwartz in 1967...

... I recall him from a colloquium dinner at Columbia in the late 70s waxing about butterflies he collected and telling stories about tigers having acquired a taste for human flesh as a consequence of the war...

... there will not be so many tigers left, but please let me continue.

\section{By all means.}

And Grothendieck went too.

And Lê Dung Tráng, who was Vietnamese.

And do not forget the Fields medalist Ngô Báo Châu at Hyderabad. Vietnam has by now come on its own.

\section{He was educated in Paris and did his work there.}

This reminds me of what I was going to respond to one of your initial remarks. It is not good to educate people and have them leave permanently. Good maybe for the individual, as you pointed out, but bad for the country. On the other hand, having them return home is not always good either. Invariably they will be isolated and wither. One solution is that they should divide their time between the West for their own mathematical inspiration and their homes to make their countries benefit. In this way they will achieve the best of two worlds.

\section{Seems an excellent idea.}

I know quite a few very good mathematicians from India who have a position in the West and return to their home country on a regular basis and teach there. On the opposite, the mathematicians who left Iran without completing their military service, like Caucher Birkar (his name was Feridoun Derakhshani, he changed it for "immigrant mathematician" in Kurdish) cannot go back to their country of birth. As to other countries I have had much experience with Cambodia. Good and bad. The main public uni- 
versity is really weak, the private ones and the Institut de Technologie du Cambodge are better. The people at the public ones are so badly paid that they all teach in some of the private institutions, which hence cannot be much better. However there are more than a dozen young $\mathrm{PhD}$ holders in Cambodia now (there was essentially only one 14 years ago when CIMPA started to be involved). The International Science Programme (ISP) at Uppsala University (Sweden) supports a network SEAMaN (SouthEast Asia Mathematical Network) involving Cambodia, Myanmar and Laos. The first five editions (2008-2012) of the International Conference on Mathematics and Mathematics Education in Developing Countries took place in Cambodia, the next five editions (2013-2017) were organized in Myanmar. Starting in November 2018 they will take place in Laos.

In Bangladesh there is an International Mathematics Conference (under the slogan Bridging South Asian Mathematicians) every second year. There are several universities there including a brand new German University of Bangladesh supported by German funds.

\section{And Malaysia?}

There is one ERCE in Kuala Lumpur and several universities with a good level in mathematics - but not at the level of their neighbour Singapore, which is outstanding, like Hong Kong. Thailand has a larger number of mathematicians and several quite good universities. In terms of number of publications, Malaysia, Thailand, Indonesia and the Philippines are among the most productive.

\section{But they might have the requisite educational infra- structure.}

Then we should not forget the Philippines which are doing fine, thanks to the international support which started more than twenty years ago. And Pakistan where we had a remarkable institute in Lahore once - this was the very first ERCE. But, after the previous director left, it is no more at an international level and has lost its label. Yet, thanks to it, there are many mathematicians in most universities of Pakistan with a good research record.

It is interesting that Pakistan has diverged so much from India after the partition. But it was funded as a specifically Islamic state, while India ostensibly was secular and multi-cultural, although this is changing as of late. Still Pakistan is very similar to India, and I do not think that the religious character of the state has had much effect on science and technology. True, there is no Tata Institute in Pakistan, but parts of India, especially in the east, are intellectually backwards and we can perhaps make a difference. Burma (Myanmar) opened only recently. Besides, IMU and CIMPA support a very promising initiative called the Nepal Algebra Project: for six years a course on Galois theory has been taught in Tribhuvan University (Kathmandu) by five mathematicians for two weeks each. At the end of this program the same course will be taught by local staff of the university. We also care about more remote places like Mongolia, where a program of cooperation in mathematics is supported by CIMPA.
What about the Arabian peninsula? Saudi Arabia has a lot of money to throw around. Would that not be an excellent place for a research institution to serve not only it but also the surrounding Arab countries?

It is true that Saudi Arabia, by virtue of its financial muscle, is trying to establish themselves by importing not only goods but human resources. You know of course of the Faisal Prize, no doubt coming with a ridiculously high sum of money, and they hire foreigners, pay them very well, and for the duration of their appointed stay, relieve them of their passports.

\section{But there is no tradition in Saudi Arabia.}

None that I know of. In this part of the world Oman seems to be the best location in terms of research.

\section{What about other Mid-Eastern countries?}

Jordan was surprisingly good when I visited it. Much better than Lebanon, but the latter was racked by a nasty civil war, and people, including academics tend to fight each other for the most obscure reasons that make no sense to outsiders. In Syria, there were several active mathematics departments - I am afraid that this is no longer the case.

\section{When was that?}

It was in 2003, way before the civil war. And then there was Iraq.

\section{When was that?}

Early on. I actually visited twice: in 2000, 2002. It was during the time of Saddam Hussein. When I arrived at the ICM in Beijing thereafter I was severely upbraided by a compatriot who found it very inappropriate that while I was representing France in my capacity as the President of the French Mathematical Society, I went to Saddam Hussein's Iraq. Anyway, Iraq has an old tradition in mathematics, and there were several very active universities. We found four promising students, two of them women by the way, and asked to bring them to Paris. The Iraqi authorities insisted that the women travel either with their husbands or fathers. One husband tagged along and the other woman managed to get away somehow. She is now back in Iraq doing a very good job. She organizes workshops supported by CIMPA in the Kurdish part of Iraq. Caucher Birkar, who just received a Fields Medal in Rio, is one of the teachers of these workshops.

\section{Egypt?}

Egypt is exceptional for me as it is a country I went for purely touristic reasons. But I plan to participate in an ICTP research school there in two or three years.

\section{We could go on for a long time.}

Yes we could.

But I guess we will not. Thank you very much for your time.

No problem. I really want this to become better known. 